\title{
Experimental study on the effects of used HEPA filters on water environment
}

\author{
Yunquan Liu ${ }^{1,2}$, Sanxi Peng ${ }^{3}$, Huimei Shan ${ }^{1,2, *}$, Yanlian Zhao ${ }^{1,2}$ \\ ${ }^{1}$ Guangxi Key Laboratory of Environmental Pollution Control Theory and Technology, Guilin University of Technology, Guilin \\ 541004, China \\ ${ }^{2}$ Collaborative Innovation Center for Water Pollution Control and Water Safety in Karst Area, Guilin University of Technology, \\ Guilin 541004, China \\ ${ }^{3}$ College of Earth Science, Guilin University of Technology, Guilin 541004, China
}

\begin{abstract}
In this paper, the commonly used High Efficiency Particulate Air filter (HEPA) material as the research object, through the design of indoor experiment, using pure water, groundwater, and rainwater solution to soak, analysis of unused and abandoned the mesh in different water chemical solution release/adsorption law of anion and metal components, in order to find out its potential impact on the water environment. Results showed that: (1) when the waste HEPA filters were soaked in water solutions, the maximum average release amounts $\left(\overline{Q_{\max }}\right)$ of four anions were in a order as: $\mathrm{SO}_{4}{ }^{2-}>\mathrm{NO}_{3}{ }^{-}>\mathrm{Cl}^{-}>\mathrm{F}^{-}$. Pure waters showed the highest $\left(\overline{Q_{\max }}\right)$ of $\mathrm{Cl}^{-}$and $\mathrm{NO}_{3}{ }^{-}$, which were 1.2120 and $0.3387 \mathrm{mg} / \mathrm{g}$, respectively. Groundwater showed the highest $\left(\overline{Q_{\max }}\right)$ of $\mathrm{SO}_{4}{ }^{2-}$ and $\mathrm{F}^{-}$, which were 6.7329 and $0.0348 \mathrm{mg} / \mathrm{g}$. These indicated that $\mathrm{SO}_{4}{ }^{2-}$ was the major anion pollutant for waste HEPA filters soaked in water solutions, and groundwater and pure water were more susceptible to be contaminated by anions released from waste HEPA filters. (2) the $\left(\overline{Q_{\max }}\right)$ of three metals released from waste HEPA filters were in a order as $\mathrm{Zn}>\mathrm{Pb}>$ As, in which, groundwater showed the highest $\left(\overline{Q_{\max }}\right)$ of $\mathrm{Zn}(2.21 \mu \mathrm{g} / \mathrm{g})$, followed by rainwater and pure water. This meant that $\mathrm{Zn}$ is the major heavy metal pollutant released from waste HEPA filters into the water environment, and groundwater was more susceptible to be contaminated by metals released from waste HEPA filters. (3) None $\mathrm{Zn}, \mathrm{Pb}$, and As were released in these three different solutions for the unused filter, indicating that it has almost no contamination threat to the water environment. This study is expected to further improve the understanding of water environmental pollution prevention and management, and provide a theoretical basis for China's ecological environment protection.
\end{abstract}

\section{Introduction}

With the rapid development of China's economy, the problem of air pollution is becoming more and more serious. In 2002, the World Health Organization (WHO) released a report which pointed out that $50 \%$ of the people in the world live in an environment with serious air quality problems", and listed air pollutants as one of the most dangerous environmental carcinogens. The main pollutants in the air include particulate matter (PM), gaseous matter, volatile and semi-volatile matter [1]. Among them, PM caused the most prominent environmental pollution and threats to human health. Although fine particulate aerosols have a small particle size and large surface area, they are easier to absorb pollutants in the air than large particulate pollutants [2]. As the content of particulate matter in the atmospheric environment increases, the process of sunlight irradiation is absorbed and obscured by particulate matter, etc [3], which reduces the illumination on plants and affects the photosynthesis and respiration of plants. In addition, the settlement of atmospheric particulate matter has a serious impact on the quality of soil, resulting in changes in soil $\mathrm{pH}$, reduced nutrient content in the soil, and caused serious damage to the growth of plants and crops in the soil [4]. In February 2013, nearly 2 million square kilometers of the central and eastern Pearl River Delta experienced severe smog. From February 20 to 26, 2014, the hourly concentration of $\mathrm{PM}_{2.5}$ exceeded $550 \mu \mathrm{g} / \mathrm{m}^{3}$ at some air monitoring stations in Beijing. Far beyond the limits of China's Ambient Air Quality Standard (GB3095-2012) $\left(75 \mu \mathrm{g} / \mathrm{m}^{3}\right)$. The average annual $\mathrm{PM}_{2.5}$ concentration in Shanghai exceeded the gb3095-2012 standard limit for three consecutive years from 2014 to 2016. Statistical data from the Health Bureau found that: severe haze weather leads to a significant increase of 2 5 times patients in the respiratory department. PM can absorb a large number of carcinogens and genotoxic mutagenesis, easily entering the human body through nasal and oral respiration, leading to aggravation of chronic diseases, aggravation of respiratory and heart diseases, change of lung function and structure, the influence of reproductive ability and even change of human immune structure $[5,6]$. A Chinese study of 26 cities found that 4.47 percent of daily emergency hospital visits can be attributed to $\mathrm{PM}_{1}$ pollution [7]. An

\footnotetext{
${ }^{*}$ Corresponding author: shanhuimei@glut.edu.cn
} 
increase of $10 \mu \mathrm{g} / \mathrm{m}^{3} \mathrm{PM}_{2.5}$ in the environment was associated with a $10 \%$ increase in all-cause mortality and a 3\% 76\% increase in cardiovascular mortality [8].

In the research of air pollution-related topics in China, the research started late, the monitoring of air pollution particles was late, and the standard formulation level was relatively broad and low efficiency, which seriously affected the progress of air pollution control in China. Therefore, it is necessary to strengthen the prevention and control measures of atmospheric particulate pollutants [9]. How to efficiently control and remove $\mathrm{PM}$ in the air is also a hot spot for many researchers. Currently, one of the mainstream machines for the removal of PM in the air is the High-Efficiency Particulate Air Filter (HEPA) technology [10]. There are many kinds of materials composed of HEPA, which can be roughly divided into glass fiber high-efficiency filter paper, polypropylene (PP) filter paper, and PET filter paper. Filter screen materials mainly include glass fiber, polyester, and polypropylene. Through hundreds of regular pleats, the HEPA filter is $99.99 \%$ efficient for PM with a diameter of $0.3 \mu \mathrm{m}$ and above. The disadvantage is that the validity period is short, the use of $6 \sim 12$ months after the need to update the screen in time. Although many scholars at home and abroad have carried out a large number of studies on PM filtering materials, purification technology, and effects [11-18], less attention has been paid to the potential environmental pollution of the discarded HEPA filter screen. Research showed that the composition of PM in addition to carbon and water in the air, also contains $\mathrm{SO}_{4}{ }^{2-}, \mathrm{NH}_{4}{ }^{+}$, and $\mathrm{NO}_{3}{ }^{-}, \mathrm{Na}, \mathrm{Ca}$, oxalic acid salt, $\mathrm{Fe}, \mathrm{Cl}^{-}$, methyl sulfonate, zinc, $\mathrm{Al}, \mathrm{B}, \mathrm{Mg}, \mathrm{K}, \mathrm{Ni}$, succinic acid salt, V, Cu, Pb, Ba, Ti, Mn, Co, Sb, As, Se, Mo, Sr, Ag, $\mathrm{Cd}, \mathrm{Rb}, \mathrm{Li}, \mathrm{Bi}, \mathrm{Tl}$ and $\mathrm{Th}$ [19]. The analysis results of $\mathrm{PM}_{0.1}$ and $\mathrm{PM}_{2.5}$ in the atmospheric samples of $\mathrm{Xi}$ 'an urban area and An Kang rural area show that: Water-soluble ion in urban area PM is mainly composed of $\mathrm{NO}_{3}{ }^{-}, \mathrm{SO}_{4}{ }^{2-}$ and $\mathrm{Na}^{+}$, accounting for $16 \%$ of the total water-soluble ion concentration, respectively, $20 \%$ and $26 \%$, and the water-soluble ion in the rural sample mainly for $\mathrm{SO}_{4}{ }^{2-}, \mathrm{Na}^{+}$, and $\mathrm{Ca}^{2+}$, accounted for $23 \%$, $38 \%$ and $13 \%$ of total ion concentration, moreover, urban areas and rural atmosphere also detect the PAHs in the PM, and the average concentration of the former $\left(207.1 \mathrm{ng} / \mathrm{m}^{3}\right)$ is significantly higher than the latter $(66.9$ $\mathrm{ng} / \mathrm{m}^{3}$ ) [20]. The concentration range of PAHs in atmospheric $\mathrm{PM}_{2.5}$ in Urumqi was $0.60-32.65 \mathrm{ng} / \mathrm{m}^{3}$, $0.89-89.89 \mathrm{ng} / \mathrm{m}^{3}$, and $0.45 \sim 391 \mathrm{ng} / \mathrm{m}^{3}$, respectively, and the mean values of the three points were $6.60 \mathrm{ng} / \mathrm{m}^{3}$, $17.79 \mathrm{ng} / \mathrm{m}^{3}$, and $47.89 \mathrm{ng} / \mathrm{m}^{3}$, respectively. The concentrations of the three levels were below the limit, 17.14 percent and 25.81 percent, respectively. The PAHs in the air $\mathrm{PM}_{2.5}$ of Urumqi were mainly in the fourth and fifth rings, and the seasonal variation of PAHs in the air $\mathrm{PM}_{2.5}$ of the three points showed the characteristics of $>$ in winter, $>$ in spring, and $>$ in autumn and summer. It can be seen that the pollution of PAHs in atmospheric $\mathrm{PM}_{2.5}$ is related to its chemical properties, anthropogenic emissions, and meteorological conditions. Human activities, especially industrial activities, have a great influence on the concentration of PAHs, and the adverse effect of industrial activities on the concentration of $\mathrm{PM}_{2.5}$ in the air in winter is intensified by the air diffusion conditions [21]. MarGA aerosol ion composition data with high temporal resolution were used to analyze the characteristics of secondary ions in the Shandong Jianzhu University site during the heavy pollution period from December 16 to December 30, 2016, the variation trend of each water-soluble component was consistent with that of $\mathrm{PM}_{2.5}$. When $\mathrm{PM}_{2.5}$ concentration increased, $\mathrm{SO}_{4}{ }^{2-}$ increased the most obviously, followed by $\mathrm{NO}_{3}{ }^{-}$and $\mathrm{NH}_{4}{ }^{+}$. Nitrate and sulfate are the main contribution components in the heavy pollution process [22]. With the rapid development of the economy and society, China's air purifier market is increasingly prosperous. At the same time, a large number of discarded HEPA filters have been produced. If effective treatment measures are not taken, pollutants such as PM originally adsorbed on the filter screen will be leached or dissolved by water, and various inorganic or organic pollutants may be released through desorption or dissolution, which will pollute the water environment and bring serious threats to people's health and life.

Because of the above problem, this paper with the HEPA filter is commonly used in air purification device as the research object, using different chemical water solution (pure water, groundwater, and rainwater) on unused and abandoned HEPA filter soak, contrast analysis of HEPA filter in different water chemical composition and characteristics of the environment to release pollutants reveals its influence on the potential of water environment pollution, which provide a reference for ecological environment protection and the prevention and control of water pollution in our country.

\section{Experiments and methods}

\subsection{Material}

The HEPA filter screen (Figure 1) is taken from the air purification device produced by Shenzhen PureMate Corp, among which the discarded HEPA filter screen is taken from the air filtration device that has been operated for about 6 months in the $8 \mathrm{~m}^{3}$ experimental chamber. The pure water solution was prepared by MilliQDwect 8 (USA), and the groundwater and rainwater were collected in Yanshan District, Guilin City.

\subsection{Methods}

2.5g unused HEPA filter screen and waste filter screen were placed into several $250 \mathrm{~mL}$ serum bottles. $250 \mathrm{~mL}$ pure water, groundwater, and rainwater solution were added respectively. The solution was collected and filtered through a $0.45 \mathrm{~m}$ filter membrane after $1,3,5,7,10$ and 60 days. Two parallel experiments were designed for each group.

The content of heavy metals $\mathrm{Zn}, \mathrm{Pb}$, and Metal-like As was determined by inductively coupled plasma mass spectrometer (ICP-MSNEXion350, PerkinElmer), and the content of conventional anions 
was determined by ion chromatography (ICS2100, Diane). All experiments and tests were completed in Guangxi Key Laboratory: Environmental Pollution Control Theory and Technology Laboratory.

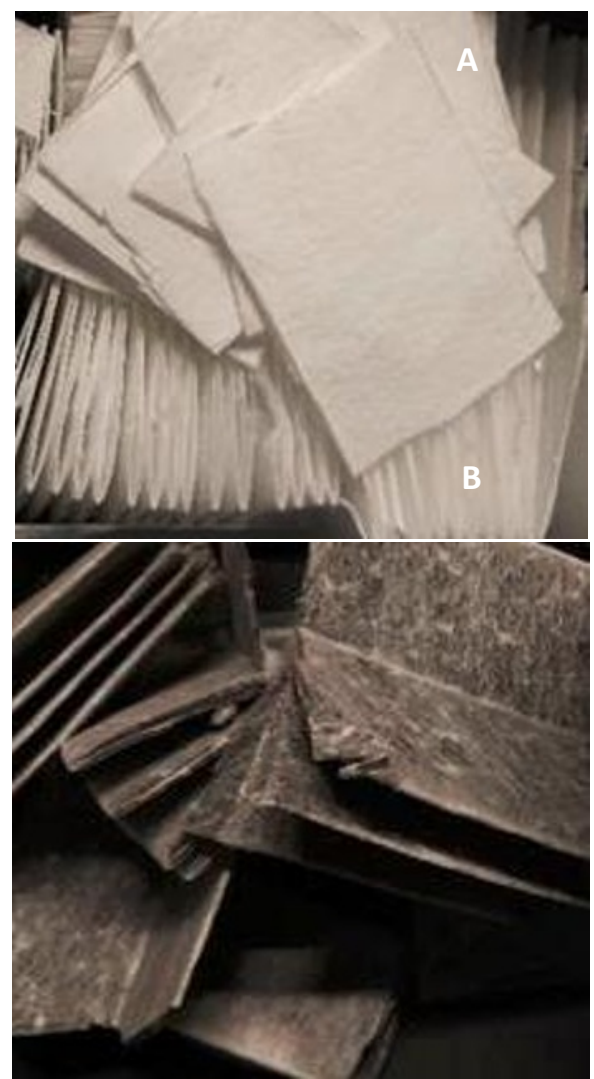

Figure. 1. Photos of not used (A) and discarded (B) HEPA filter materials

$\mathrm{Q}(\mathrm{mg} / \mathrm{g}$ or $\mu \mathrm{g} / \mathrm{g})$ of a certain chemical component (anion, metal, or metal-like) released or absorbed by a unit mass HEPA screen during immersion is calculated by the following formula:

$$
Q=\left(C_{t}-C_{0}\right) \times V / m
$$

Where, $C_{0}$ : the concentration of a chemical component in the solution at the initial moment, $\mathrm{mg} / \mathrm{L}$; $C_{t}$ : the concentration of a chemical component in the solution at the time of soaking $\mathrm{t}, \mathrm{mg} / \mathrm{L} ; V$ : the total volume of the soaking solution, $\mathrm{L}$ or $\mathrm{mL}$; $\mathrm{m}$ : the mass of the screen, g. $Q>0$ indicates that the filter releases chemical components into the solution, and the larger $Q$ is, the greater the release amount is. $Q<0$ indicates that the chemical composition in the solution is meshed adsorption, $Q$ is smaller, the greater the $|Q|$, the greater the adsorption quantity.

The experimental results of average with $\bar{Q}$ said, $\bar{Q}=\left(Q_{1}+Q_{2}\right) / 2, Q_{1}$, and $Q_{2}$ are the results of two parallel experiments respectively.

\section{Results and Discussion}

\subsection{Release characteristics of anions under different solution soaking conditions}

Unused HEPA filter and abandoned mesh in the process of pure water, groundwater, and rainwater solution soak anion release/adsorption quantity along with the change of time curve as shown in Figure 2, 3, and 4, respectively, in the process of the reaction maximum average release/adsorption $\left(\overline{Q_{\max }}\right)$ data listed in table 1 . It can be seen from the figure and table that:

(1) Under the soaking condition of pure water solution, both an unused HEPA filter and waste filter can release anions $\mathrm{F}^{-}, \mathrm{Cl}^{-}, \mathrm{NO}_{3}^{-}$and $\mathrm{SO}_{4}{ }^{2-}$ (Figure 2). With the increase of time, the release quantities of $\mathrm{F}^{-}, \mathrm{Cl}^{-}$, $\mathrm{NO}_{3}{ }^{-}$and $\mathrm{SO}_{4}{ }^{2-}$ all showed a trend of significant increase at first, then a slight decrease, and then a gradual increase. The whole reaction process, the abandoned mesh is more than the number of unused screen release anion, the former $\mathrm{F}^{-}, \mathrm{Cl}^{-}, \mathrm{NO}_{3}$-and $\mathrm{SO}_{4}{ }^{2-}\left(\overline{Q_{\max }}\right)$ were $0.0311 \mathrm{mg} / \mathrm{g}, 0.3387 \mathrm{mg} / \mathrm{g}, 1.2120 \mathrm{mg} / \mathrm{g}$ and 6.6953 $\mathrm{mg} / \mathrm{g}$, the latter only $0.0173 \mathrm{mg} / \mathrm{g}$, respectively, 0.2101 $\mathrm{mg} / \mathrm{g}, 0.6765 \mathrm{mg} / \mathrm{g}$ and $1.5584 \mathrm{mg} / \mathrm{g}$.

(2) Under the immersion condition of an underground aqueous solution, the unused screen releases a small amount of $\mathrm{Cl}^{-}, \mathrm{NO}_{3}{ }^{-}$and $\mathrm{SO}_{4}{ }^{2-}$, but a small amount of $\mathrm{F}^{-}$will be absorbed from the solution at the initial stage $(0 \sim 7 d)$. Abandoned mesh to solution has been released $\mathrm{F}^{-}, \mathrm{Cl}^{-}, \mathrm{NO}_{3}^{-}$and $\mathrm{SO}_{4}{ }^{2-}$, and with the increase of time, the $\mathrm{F}^{-}$to release a quantity to present a significant increase in the first (0 3d) slightly lower after $(>5 \mathrm{~d})$ gradually increasing trend, $\mathrm{Cl}^{-}$and $\mathrm{SO}_{4}{ }^{2-}$ release quantity of increased significantly $(0 \sim 5 \mathrm{~d})$ before they are slightly reducing the trend to remain unchanged, $\mathrm{NO}_{3}^{-}$to release a quantity to increase significantly after $(0 \sim 5 \mathrm{~d})$ basic stable. During the whole reaction process, the number of anions released by the waste filter is more than that of the unused filter. The $\left(\overline{Q_{\max }}\right)$ of the former $\mathrm{F}^{-}, \mathrm{Cl}^{-}, \mathrm{NO}_{3}{ }^{-}$and $\mathrm{SO}_{4}{ }^{2-}$ are $0.0348 \mathrm{mg} / \mathrm{g}, 0.1867 \mathrm{mg} / \mathrm{g}$, $0.8530 \mathrm{mg} / \mathrm{g}$ and $6.7329 \mathrm{mg} / \mathrm{g}$, respectively, while the latter are only $0.0037 \mathrm{mg} / \mathrm{g}, 0.1193 \mathrm{mg} / \mathrm{g}, 0.1413 \mathrm{mg} / \mathrm{g}$ and $0.8501 \mathrm{mg} / \mathrm{g}$, respectively.

(3) Under the soaking condition of the rainwater solution, the unused filter mainly adsorbs a small amount of $\mathrm{F}^{-}, \mathrm{Cl}^{-}, \mathrm{NO}_{3}{ }^{-}$and $\mathrm{SO}_{4}{ }^{2-}(\mathrm{Q}<0)$ from the solution. The discarded filter screen mainly released anions into the solution. With the increase of time, the release amounts of $\mathrm{F}^{-}, \mathrm{Cl}^{-}$and $\mathrm{SO}_{4}{ }^{2-}$ showed a trend of significant increase at first and then slightly reduced to unchanged, while the release amounts of $\mathrm{NO}_{3}^{-}$first increased significantly and then tended to be stable. The abandoned mesh of $\mathrm{F}^{-}, \mathrm{Cl}^{-}, \mathrm{NO}_{3}{ }^{-}$and $\mathrm{SO}_{4}{ }^{2-}\left(\overline{Q_{\max }}\right)$ were $0.0149 \mathrm{mg} / \mathrm{g}, 0.0589 \mathrm{mg} / \mathrm{g}, 0.6210 \mathrm{mg} / \mathrm{g}$ and 5.8272 $\mathrm{mg} / \mathrm{g}$, unused HEPA filter for more than four largest average ion adsorption capacity were $0.0067 \mathrm{mg} / \mathrm{g}$, $0.0878 \mathrm{mg} / \mathrm{g}, 0.2985 \mathrm{mg} / \mathrm{g}$ and $0.3700 \mathrm{mg} / \mathrm{g}$.

On the whole, in the immersion process of the pure water solution and underground aqueous solution, the unused screen mainly releases $\mathrm{F}^{-}, \mathrm{Cl}^{-}, \mathrm{NO}_{3}{ }^{-}$and $\mathrm{SO}_{4}{ }^{2-}$, while in rainwater solution, it mainly adsorbs anions. Mesh in three different wastewater chemistry in the solution of anionic $\left(\overline{Q_{\max }}\right)$ sorting are: $\mathrm{SO}_{4}{ }^{2-}>\mathrm{NO}_{3}{ }^{-}>\mathrm{Cl}^{-}$ $>\mathrm{F}^{-}$, means that $\mathrm{SO}_{4}^{2-}\left(\overline{Q_{\max }}\right)=6.7329 \mathrm{mg} / \mathrm{g}$ is abandoned screen potential pollution impact on the water environment of AB's main ingredient. 

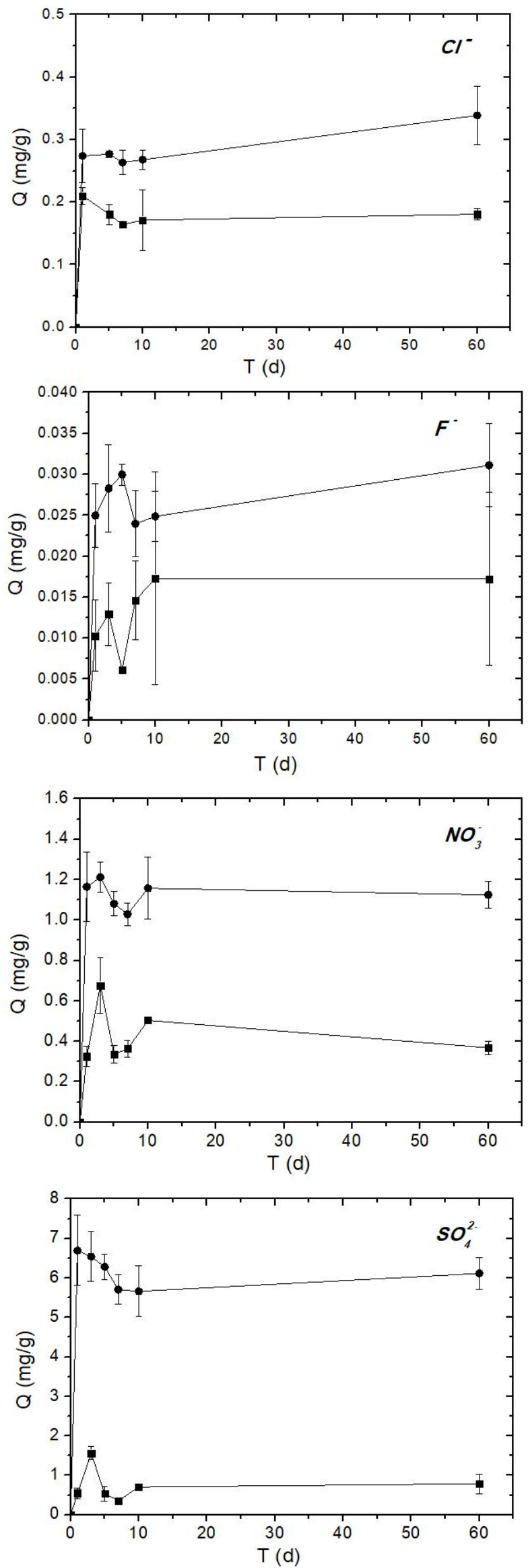

Figure 2. Curve of anion release of HEPA filter screen with time under pure water immersion ( $\square$ Unused; $\bullet$ Abandoned)
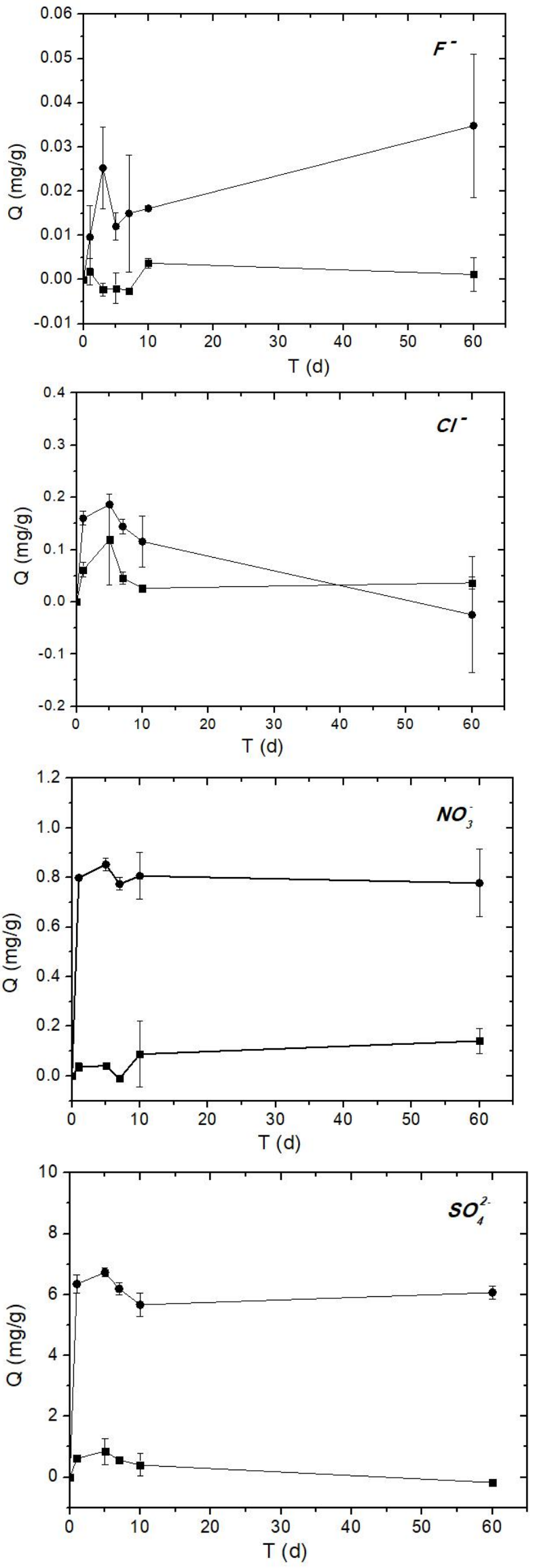

Figure 3. Change curve of anion release amount of HEPA filter screen with time under groundwater immersion (- unused; $\bullet$ Abandoned) 

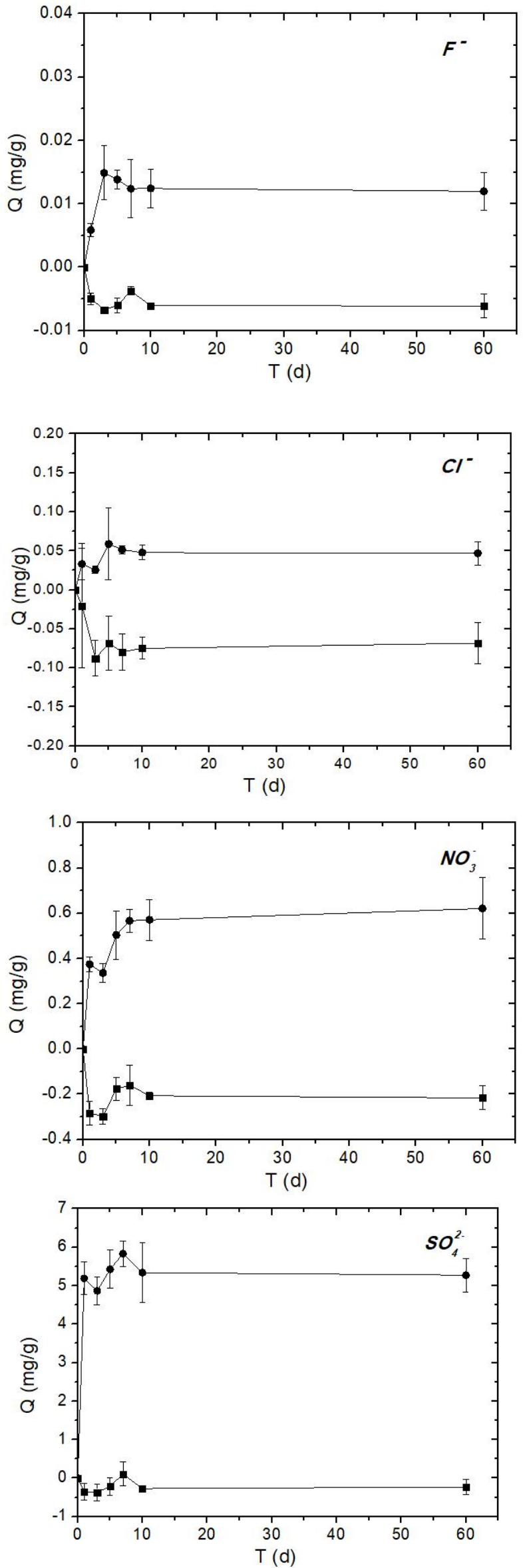

Figure 4. The curve of the anion release amount of HEPA filter under rainwater immersion with time (• Unused; $\bullet$ Abandoned)
Table 1. HEPA filter in the process of different soaking solution of anionic adsorption maximum average release $\left(\overline{Q_{\max }}\right)$ (unit: $\mathrm{mg} / \mathrm{g}$ )

\begin{tabular}{|c|c|c|c|c|c|c|c|c|}
\hline \multirow{2}{*}{$\begin{array}{c}\text { Soak } \\
\text { solut } \\
\text { ion }\end{array}$} & \multicolumn{4}{|c|}{$\begin{array}{c}\text { Unused HEPA filter } \\
\text { membrane * }\end{array}$} & \multicolumn{4}{c|}{$\begin{array}{c}\text { Waste HEPA filter } \\
\text { membrane * }\end{array}$} \\
\cline { 2 - 9 } & $\mathrm{F}^{-}$ & $\mathrm{Cl}^{-}$ & $\mathrm{NO}$ & $\mathrm{SO}$ & $\mathrm{F}^{-}$ & $\mathrm{Cl}^{-}$ & $\mathrm{NO}$ & $\mathrm{SO}$ \\
$3^{-}$ & $4^{2-}$ \\
\hline pure & +0.017 & +0. & +0. & +1. & +0. & +0. & +1. & +6. \\
water & 3 & 210 & 676 & 558 & 031 & 338 & 212 & 695 \\
& 1 & 5 & 4 & 1 & 7 & 0 & 3 \\
\hline grou & +0.003 & +0. & +0. & +0. & +0. & +0. & +0. & +6. \\
ndwa & $7 /-0.00$ & 119 & 141 & 850 & 034 & 186 & 853 & 732 \\
ter & 25 & 3 & 3 & 1 & 8 & 7 & 0 & 9 \\
\hline rainw & -0.006 & -0. & -0. & -0. & +0. & +0. & +0. & +5. \\
ater & 7 & 087 & 298 & 370 & 014 & 058 & 621 & 827 \\
& 8 & 5 & 0 & 9 & 9 & 0 & 2 \\
\hline
\end{tabular}

* Note: in the table, + represents the release amount and represents the adsorption amount

\subsection{The release rule of $\mathrm{Zn}, \mathrm{Pb}$, and $\mathrm{As}$ under different solution immersion}
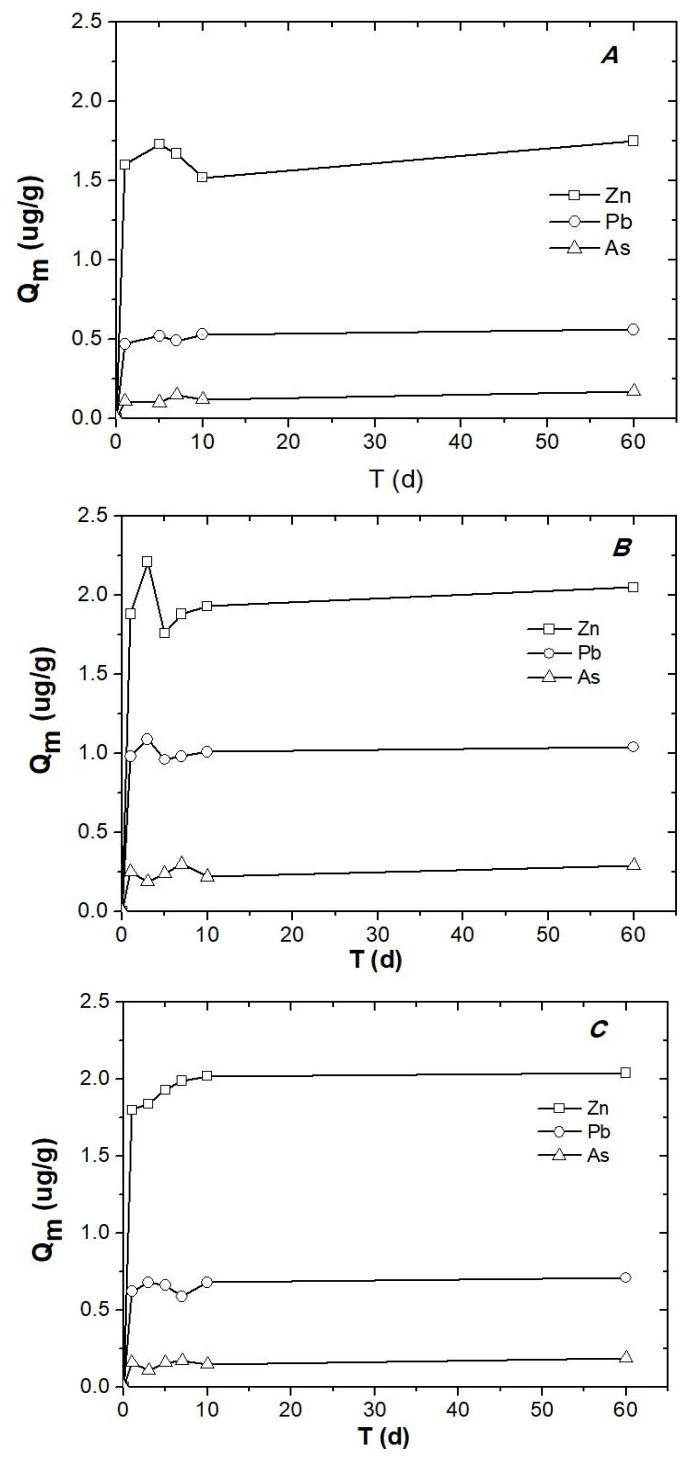

Figure 5. The change curve of the release amount of $\mathrm{Zn}, \mathrm{Pb}$, and As in the waste HEPA filter screen with time under different immersion solutions (A: pure water; B: Groundwater; C: Rainwater) 
In different solution soaking processes, the release amount of $\mathrm{Zn}, \mathrm{Pb}$, and $\mathrm{As}$ from the unused filter, the screen is 0 . Therefore, this paper only plots the change curve of the release amount of anions with time in the process of soaking pure water, groundwater, and rainwater solution, as shown in Figure 5. It can be seen from the figure that:

(1) In pure water solution, with the increase of soaking time, the release of $\mathrm{Zn}$ first increased significantly $(0 \sim 5 \mathrm{~d})$, then decreased slightly $(5 \sim 10 \mathrm{~d})$ and then increased slowly, while the release of $\mathrm{Pb}$ and $\mathrm{As}$ showed a trend of rapid increase $(0 \sim 1 \mathrm{~d})$ and then slowly increased (1 10d) and tended to be stable.

(2) In the underground aqueous solution, with the increase of soaking time, the release of $\mathrm{Zn}$ and $\mathrm{Pb}$ showed a significant increase $(0 \sim 3 \mathrm{~d})$ and then a slight decrease, and then a slow increase $(5 \sim 10 \mathrm{~d})$ to tend to be stable, while the release of As showed a rapid increase $(0 \sim 1 d)$ and then gradually tends to be stable.

(3) In rainwater solution, with the increase of soaking time, $\mathrm{Zn}, \mathrm{Pb}$, and As basically showed a trend of rapid increase first $(0 \sim 1 \mathrm{~d})$ and then slowly increase $(1 \sim 10 \mathrm{~d})$ to unchanged.

On the whole, a large amount of $\mathrm{Zn}, \mathrm{Pb}$, and As were rapidly released from the waste filter after immersion for 0 5 days, and the reaction tended to be stable after immersion for 10 days.

Abandoned mesh in the process of pure water, groundwater, and water solution immersion $\mathrm{Zn}, \mathrm{Pb}$, and As $\left(\overline{Q_{\max }}\right)$ As listed in table 2. From the table can be found: underground water solution of zinc, $\mathrm{Pb}$, and $\mathrm{As}$ ( $\overline{Q_{\max }}$ ) biggest, were $2.21,1.09$, and $0.30 \mathrm{mu} \mathrm{g} / \mathrm{g}$, followed by rain and water solution. This means that the groundwater is more seriously affected by the pollution caused by the release of $\mathrm{Zn}, \mathrm{Pb}$, and As from waste filters. In three different water chemical solution $\left(\overline{Q_{\max }}\right)$ sort of: $\mathrm{Zn}>\mathrm{Pb}>\mathrm{As}$, show that abandoned mesh of zinc is the main composition of heavy metal pollution of the water environment.

Table 2. The different solution soak discarded in the process of mesh for zinc, $\mathrm{Pb}$, and As the largest average release quantity $\left(\overline{Q_{\max }}\right)$ (unit: $\mu \mathrm{g} / \mathrm{g}$ )

\begin{tabular}{|l|l|l|l|}
\hline Soak solution & $\mathbf{Z n}$ & $\mathbf{P b}$ & As \\
\hline pure water & 1.75 & 0.64 & 0.17 \\
\hline groundwater & 2.21 & 1.09 & 0.30 \\
\hline rainwater & 2.04 & 0.71 & 0.19 \\
\hline
\end{tabular}

\section{Conclusions and Suggestions}

\subsection{Conclusions}

In this paper, the HEPA filter screen was taken as the research object, and laboratory experiments were designed. Different aqueous chemical solutions (pure water, groundwater, and rainwater) were used to soak the unused and abandoned filter screen, to identify the process and characteristics of pollutants released by the HEPA filter screen during the soaking process and reveal its potential impact on the water environment.
(1) Abandoned mesh in pure water, groundwater, and water solution to release more $\mathrm{F}^{-}, \mathrm{Cl}^{-}, \mathrm{NO}_{3}{ }^{-}$and $\mathrm{SO}_{4}{ }^{2-}$, $\mathrm{F}^{-}$and $\mathrm{SO}_{4}{ }^{2-}$ in which different solution of $\left(\overline{Q_{\max }}\right)$ sort: groundwater $>$ water $>$ the rain, $\mathrm{Cl}^{-}$and $\mathrm{NO}_{3}{ }^{-}$of $\left(\overline{Q_{\max }}\right)$ sorting as follows: pure water $>$ the rain of groundwater, suggests that the groundwater and water polluted by waste screen release anion more serious threat.

(2) In the solution of anionic $\left(\overline{Q_{\max }}\right)$ sorting as follows: the basic $\mathrm{SO}_{4}{ }^{2-}>\mathrm{NO}_{3}{ }^{-}>\mathrm{Cl}^{-}>\mathrm{F}^{-}$, shows that waste filter in the water environment to release the main anion composition of $\mathrm{SO}_{4}{ }^{2-}\left(\left(\overline{Q_{\max }}\right)=6.7329 \mathrm{mg} / \mathrm{g}\right)$.

(3) Abandoned mesh in the underground water solution of $\mathrm{Zn}, \mathrm{Pb}$, and $\mathrm{As}\left(\overline{Q_{\max }}\right)$ biggest, followed by in rainwater and pure water solution, shows that the groundwater environment caused by waste mesh/heavy metals pollution threat far more serious.

(4) In an aqueous solution, different weight/metals $\left(\overline{Q_{\max }}\right)$ sorting as follows: the basic $\mathrm{Zn}>\mathrm{Pb}>$ As namely abandoned HEPA filter in the release of main heavy metals in a water environment for $\mathrm{Zn}\left(\left(\overline{Q_{\max }}\right)=2.21\right.$ $\mu \mathrm{g} / \mathrm{g})$.

\subsection{Suggestions}

With the prominent problem of air pollution, the research and development market of purification technology and equipment is increasingly prosperous. At the same time, the waste filter screen produced in the purification process will gradually increase. In this study, it was found that if no effective treatment measures were taken for the abandoned HEPA filter, the abandoned filter would continuously release $\mathrm{F}^{-}, \mathrm{Cl}^{-}, \mathrm{NO}_{3}{ }^{-}$and $\mathrm{SO}_{4}{ }^{2-}$, as well as other chemical substances such as $\mathrm{Zn}, \mathrm{Pb}$ and $\mathrm{As}$, which would have a potential impact on the water environment along with the hydrological cycle. In the future, therefore, pay attention to air purification technology development at the same time, should also strengthen the environmental protection publicity and education, improve the residents' environmental protection consciousness, create a good social environment atmosphere, attaches great importance to the waste of filter harmless, specialized processing, improve the environmental protection supervision system and related laws and regulations, to avoid secondary pollution impact on the surrounding water environment, are also of great help to improve our air quality.

\section{Acknowledgments}

Funding for this research is provided by the National Natural Science Foundation of China (No. 41877194, No. 41502232), the Natural Science Foundation of Guangxi (No. 2018AD19142, No. 2018AD19204), Guilin University of Technology Program (GLUTQD 2016047), the Research Funds of the Guangxi Key Laboratory of Theory and Technology for Environmental Pollution Control (1701K010), the Research Fund for Visiting Scholar by China Scholarship Council (No. 201908450003) and Guangxi Education Department (GED). 


\section{References}

[1] Cassee F R, Héroux M E, Gerlofsnijland M E, et al. Particulate matter beyond mass: recent health evidence on the role of fractions, chemical constituents and sources of emission [J]. Inhalation Toxicology, 2013, 25(14):802-812.

[2] Wang Y, Li Y, Li Y, et al. The effect of PM2.5 on the quality of air pollution in China [J]. Central South University, 2010. (In Chinese)

[3] Yao Guoqin. Analysis on how to enhance the urban environmental management of air pollution control [J]. Smart City, 2019, 5(24):121-122. (In Chinese)

[4] CHEN Y. Study on the harm of air pollution to environment and treatment plan $[\mathrm{J}]$. Resources Conservation and Environmental Protection, 2020 (09): 136-137. (In Chinese)

[5] Haidong Kan, Bingheng Chen. Particulate air pollution in urban areas of Shanghai, China: health-based economic assessment [J]. Science of the Total Environment, 2004, 322(1):71-79. (In Chinese)

[6] Pelucchi C, Negri E, Gallus S, et al. Long-term particulate matter exposure and mortality: a review of European epidemiological studies [J]. Bmc Public Health, 2009, 9(1):453.

[7] SONG H Z. Monitoring and treatment of air pollution problem [J]. Resources Conservation and Environmental Protection, 2020, (07):81. (In Chinese)

[8] Brook R D, Rajagopalan S, Pope C A, et al. 2010. Particulate matter air pollution and cardiovascular disease: an update to the scientific statement from the American heart association [J]. Circulation, 121(21):2331-2378.

[9] MA F P. Study on prevention and treatment measures of atmospheric particulate pollutants [J]. Environment and Development, 2019, 31(11): 38-39.

[10] Niu Yan-jing, MIAO Li-ting, Zhang Shen-shen, et al.Experimental study on performance of hepa filter [J]. Journal of shenyang institute of aeronautics and astronautics, 2010, 27(02):69-72. (In Chinese)

[11] Ni Shenyang, Bai Li, LI Shuang, et al.A brief discussion on the development trend of air purifier in China [J]. Journal of changchun institute of engineering (natural science edition), 2016, 17(4) : 44-47. (In Chinese)

[12] Luna, Sun Danfeng, LUO Bangzhen, et al. Application of electrostatic dust removal technology in air purification of highway tunnel [J]. Environmental science and technology, 2017, 40(01):95-100. (In Chinese)

[13] Li Jianrong, Wang Lina, Jin Yi, et al. Research progress of air purification and disinfection technology at home and abroad [J]. Environmental science and technology, 2014, 37(S1):204-209. (In Chinese)
[14] Cao Yuanyuan, Guo Ting, Geng Chunmei, et al. New situation of indoor air pollution and pollution control technology [J]. Environmental Science and Technology, 2013, 36(S2): 229- 231+ 235. (In Chinese)

[15] Zhu Zengyin, Li Bing, Zhao Qiuyue, et al. Review and prospect of PM2.5 research and control countermeasures at home and abroad [J]. Environmental Science and Technology, 2013, 26(01): 70-74. (In Chinese)

[16] Zhang Rufan, Liu Chong, Hus Po-Chun, et al., Nanofiber Air Filters with High-Temperature Stability for Efficient PM2.5 Removal from the Pollution Sources [J]. Nano Letters, 2016, 16(6): 3642-3649. (In Chinese)

[17] Liu Chong, Hsu Po-Chun, Lee Hyun-wook, et al., Transparent air filter for high-efficiency PM2.5 capture [J]. Nature Communications, 2015, 6. (In Chinese)

[18] Bortolassi, ACC., Nagarajan, S., Lima, BD., et al., Efficient nanoparticles removal and bactericidal action of electrospun nanofibers membranes for air filtration [J]. Materials Science \& Engineering C-Materials for Biological Applications, 2019, 102:718-729.

[19] Pakkanen T, Korhonen C, Hillamo R, et al. Ultrafine particles (PM0.1) in the Helsinki area [J]. Journal of Aerosol Science, 2000, 31(Suppl 1): 522-523.

[20] Zhuo Xianqin, Gong Weijie. Pollution characteristics of particulate matter in urban and rural areas of Guanzhong in winter [J]. Journal of Environmental Engineering, 2017, 11(7): 41764182. (In Chinese)

[21] Qi Qianqian, Wu Zhihui, Peng Xiaowu, Hu Xiaohan. Pollution characteristics of polycyclic aromatic hydrocarbons (PAHs) in atmospheric PM_(2.5) in Urumqi [J]. Environmental Protection of Xinjiang, 2020, 42(04):7-12. (In Chinese)

[22] Zhang Wenjuan, Sun Xiaoyan, Li Min, Xia Zhiyong, Sun Fengjuan, Wang Zhifei, Lv Bo.Air quality characteristics and PM_(2.5) component spectrum analysis in heavy pollution period in jinan city [J]. China Population, Resources and Environment, 2018, 28(S1):71-75. (In Chinese) 